Ciência Florestal, Santa Maria, v. 22, n. 3, p. 477-491, jul.-set., 2012

ISSN 0103-9954

\title{
FENOLOGIA, MORFOLOGIA E ANÁLISE DE SEMENTES DE Apuleia leiocarpa (Vogel) J. F. Macbr.
}

\author{
PHENOLOGY, MORPHOLOGY AND ANALYSIS OF SEEDS OF \\ Apuleia leiocarpa (Vogel) J. F. Macbr.
}

\author{
Marciele Felippi ${ }^{1}$ Charles Rodrigo Belmonte Maffra ${ }^{2}$ Edison Bisognin Cantarelli ${ }^{3}$ \\ Maristela Machado Araújo ${ }^{4}$ Solon Jonas Longhi ${ }^{5}$
}

\begin{abstract}
RESUMO
Com o objetivo de agregar conhecimentos em relação à Apuleia leiocarpa (Vogel) J. F. Macbr., analisou-se sua época de floração e frutificação, a morfologia de frutos, sementes, germinação, plântula e muda, como também características físicas, germinação e emergência de sementes de diferentes árvores matrizes. A partir da seleção de 20 árvores matrizes, foram realizadas observações mensalmente, a fim de averiguar a presença de flores e frutos. Após a maturação dos frutos, estes foram coletados, suas sementes extraídas, beneficiadas e separadas por matriz, de onde foram retiradas amostras para determinação do peso, teor de água, testes germinativos e de emergência em condições de laboratório e viveiro. Exemplares de frutos e sementes foram armazenados em álcool $70 \%$, para posterior descrição morfológica. A maior presença de flores de grápia ocorreu de setembro a outubro e de frutos, de janeiro a março, havendo variações em relação à época e à frequência de árvores matrizes nas fenofases, assim como a quantidade estimada de frutos e sementes presentes em cada ano. Morfologicamente, o fruto é simples, vagem seca e indeiscente, com 1 a 2 sementes cada, sendo estas de coloração castanha, com cicatriz linear visível, rafe pouco desenvolvida e micrópila próxima ao hilo. Internamente, a semente é albuminosa, com embrião axial, espatulado, ocupando $3 / 4$ da região interna, com cotilédones foliáceos e grandes. A germinação é epígea e a plântula fanerocotiledonar. O comprimento dos frutos variou de 1,45 a $3,01 \mathrm{~cm}$, a largura de 1,20 a $2,07 \mathrm{~cm}$ e a espessura de 0,20 a 0,30 $\mathrm{cm}$. Para as sementes, 1,2 a 2,1 cm de comprimento, 0,6 a $0,95 \mathrm{~cm}$ de largura e 0,1 a 0,2 $\mathrm{cm}$ de espessura. Houve diferenças entre árvores matrizes para os testes físicos e fisiológicos, onde o número de sementes por quilograma variou de 8.713 a 11.197 , o grau de umidade de 12,43 a $27,97 \%$, a germinação de 13 a $96 \%$ e a emergência de 26 a $88 \%$. Concluiu-se que sementes provenientes de indivíduos de uma mesma população possuem variações expressivas quanto às características físicas e fisiológicas, seja em função do ambiente, fator genético ou do micro-habitat. Assim, apesar de proporcionar melhor representatividade genética, reduzem a homogeneidade do lote de sementes.
\end{abstract}

Palavras-chave: árvore matriz; germinação; grápia.

1. Bióloga, Dra ${ }^{\text {. }}$, Professora do Departamento de Ciências Biológicas, Universidade Federal do Centro-Oeste, Rua Camargo Varela de Sá, Vila Carli, CEP 85040-080, Guarapuava (PR). marciele.f@bol.com.br

2. Graduando em Engenharia Florestal, Centro de Educação Superior do Norte do Rio Grande do Sul, Universidade Federal de Santa Maria, Campus Linha 7 de Setembro, BR 386, Km 40, CEP 98400-000, Frederico Westphalen (RS). charles.mafra@hotmail.com

3. Engenheiro Florestal, Dr., Professor do Centro de Educação Superior do Norte do Rio Grande do Sul, Universidade Federal de Santa Maria, Campus Linha 7 de Setembro, BR 386, Km 40, CEP 98400-000, Frederico Westphalen (RS).engedison@yahoo.com.

4. Engenheira Florestal, Dria ., Professora Adjunta do Departamento de Ciências Florestais, Centro de Ciências Rurais, Universidade Federal de Santa Maria, Av. Roraima, 1000, Campus Universitário, CEP 97105-900, Santa Maria (RS). araujo.maristela@gmail.com

5. Engenheiro Florestal, Dr., Professor Titular do Departamento de Ciências Florestais, Centro de Ciências Rurais, Universidade Federal de Santa Maria, Av. Roraima, 1000, Campus Universitário, CEP 97105-900, Santa Maria (RS). Longhi.solon@gmail.com

Recebido para publicação em 13/04/2010 e aceito em 16/06/2011

Ci. Fl., v. 22, n. 3, jul.-set., 2012 


\begin{abstract}
In order to add knowledge regarding to Apuleia leiocarpa (Vogel) J. F. Macbr., it was analyzed its time of flowering and fruiting, fruit morphology, seed germination, seedling and changes, as well as its physical characteristics, germination and emergence of seeds of different trees. From the selection of 20 mother trees, observations were made monthly in order to ascertain the presence of flowers and fruits. After maturation, the fruits were collected, the seeds extracted from fruits, processed and separated by matrix, from which samples were taken for the determination of weight, moisture content, germination tests and emergency conditions in laboratory and nursery. Copies of fruits and seeds were stored in $70 \%$ ethanol for the later morphological description. The greater presence of Apuleia leiocarpa flowers occurred from September to October and fruits from January to March, with a variation in the time and frequency of mother trees in both clones as well as the estimated amount of fruits and seeds in each year. Morphologically, the fruit is simple, indehiscent pod and dry, with 1-2 seeds, which are brown in color with visible linear scar, micropyle and raphe undeveloped near the hilum. Internally, the seed is albuminous, with axial embryo, spatulate, occupying three quarters of the inner region, with large and foliaceous cotyledons. The germination is epigeal and the seedling phanerocotyledonal. The fruit length ranged from 1.45 to $3.01 \mathrm{~cm}$, width from 1.20 to $2.07 \mathrm{~cm}$ and thickness from 0.20 to $0.30 \mathrm{~cm}$. For the seeds, 1.2 to $2.1 \mathrm{~cm}$ long, 0.6 to $0.95 \mathrm{~cm}$ wide and 0.1 to $0.2 \mathrm{~cm}$ thick. There were differences between the parent trees for the physical and physiological tests, where the number of seeds per kilogram ranged from 8,713 to 11,197 , the moisture content from 12.43 to 27. $97 \%$ germination 13 to $96 \%$ and the emergengc from 26 to $88 \%$. It was concluded that seeds from individuals of the same population have significant physical and physiological variations, either because of environmental or genetic factors or due to the micro habitat. Thus, although providing better genetic representation, they reduce the homogeneity of the seed lots.
\end{abstract}

Keywords: matrix tree; germination; Apuleia leiocarpa.

\section{INTRODUÇÃO}

A intensa atividade humana tem resultado na alteração de vários ambientes naturais. No Brasil, regiões de matas cederam lugaràs terras de cultura eà construção civil, levando ao quase desaparecimento de espécies vegetais econômica e ecologicamente importantes (SOUZA e MOSCHETA, 1992).

Para reverter este quadro é necessário conservar os remanescentes florestais, além de restaurar áreas alteradas. A definição de métodos e estratégias, que permitam a produção de mudas de qualidade em um curto período de tempo e em condições acessíveis, é de fundamental importância (CUNHA et al., 2005). No entanto, esta ação depende de conhecimentos ecológicos e botânicos relacionados às espécies (CORREIA et al., 2005), como também ao tamanho da amostragem genética da população (MORI, 2003) e à procedência das matrizes (PIÑA-RODRIGUES et al., 2007).

Apesar do desenvolvimento de técnicas para a melhor propagação vegetal ser conhecida, grande parte das espécies nativas brasileiras necessita de informações silviculturais básicas, já que a silvicultura brasileira, até o presente, restringiu-se às espécies exóticas, por terem atendido melhor as necessidades industriais em produtividade (SCHNEIDER et al., 2000).

Portanto, neste trabalho, buscaram-se informações acerca de Apuleia leiocarpa (Vogel) J. F. Macbr. (Fabaceae - Caesalpinioideae), típica do Rio Grande do Sul, reconhecida pela qualidade da madeira, potencial apícola, medicinal, paisagístico e florestal. Conhecida como grápia, possui aproximadamente $35 \mathrm{~m}$ de altura e $100 \mathrm{~cm}$ de diâmetro a altura do peito (DAP) (CARVALHO, 2003).

Apesar da ampla distribuição geográfica no território brasileiro, atualmente a presença da espécie é descontínua, devido à devastação intensa das matas e à falta de reposição (MATTOS e GUARANHA, 1983). Também não há informações suficientes relacionadas à qualidade das sementes para a produção de mudas em grande escala. Sendo assim, há necessidade de acrescentar dados referentes à produção de mudas de Apuleia leiocarpa (Vogel) J. F. Macbr.

O objetivo deste trabalho foi identificar a época de floração e frutificação, descrever e ilustrar os aspectos morfológicos externos e internos de frutos e sementes e os aspectos externos de plântulas 
e mudas, além da análise física, germinação e a emergência de sementes de diferentes árvores matrizes de Apuleia leiocarpa (Vogel) J. F. Macbr.

\section{MATERIAL E MÉTODOS}

O estudo foi realizado durante o período de março de 2007 a março de 2010, sendo que o material botânico e as observações fenológicas foram obtidos no Município de Frederico Westphalen $\left(27^{\circ} 24^{\prime} 01,67^{\prime \prime} \mathrm{S} ; 53^{\circ} 25^{\prime} 51,75^{\prime}\right.$ 'W), Rio Grande do Sul, em duas áreas, de 60,34 ha e 50 ha, situadas a uma distância de $3 \mathrm{~km}$ da sede do município.

A cobertura florestal da região pertence ao domínio da Floresta Estacional Decidual e se encontra a $566 \mathrm{~m}$ de altitude, com classificação climática, segundo Köppen, do tipo Cfa, precipitação média anual entre 1.800 e $2.100 \mathrm{~mm}$ e temperatura média anual em torno de $18{ }^{\circ} \mathrm{C}$ (SEMA, 2001).

Para o presente trabalho foram obtidos, junto à Estação Meteorológica do Centro de Ensino Superior Norte do Rio Grande do Sul (CESNORS), dados climáticos (temperatura e pluviometria) referentes ao período de estudo (Figura 1). Informações sobre a pluviometria somente foram observadas a partir do ano de 2008.

As análises morfológicas de frutos e sementes e os testes físicos e fisiológicos com sementes foram realizados no laboratório de sementes do Departamento de Ciências Florestais na Universidade Federal de Santa Maria (UFSM) e no viveiro do CESNORS, UFSM, Campus Frederico Westphalen, RS.

\section{Registro dos aspectos fenológicos e coleta do material botânico}

$\mathrm{Na}$ área de estudo, foram percorridas faixas, onde foram selecionadas 20 árvores matrizes, aparentemente sadias, com copa bem distribuída e fuste reto. A distância mínima de $100 \mathrm{~m}$ entre as árvores seguiu sugestão de Piña-Rodrigues (2002) e Mori (2003) e foi mantida com o objetivo de reduzir a frequência de captura de gene raro, buscando a qualidade genética, assim como a físico-fisiológica das sementes, conforme Piña-Rodrigues et al. (2007).

As árvores marcadas foram monitoradas mensalmente, com o auxílio de binóculo e escalagem até próximo à copa, onde se observou a presença de cada fenofase, seguindo o método qualitativo utilizado por Fournier (1974).

A floração foi classificada, conforme Morellato et al. (1989), como o período em que as árvores possuíam flores em antese e a frutificação, quando os frutos estavam maduros.

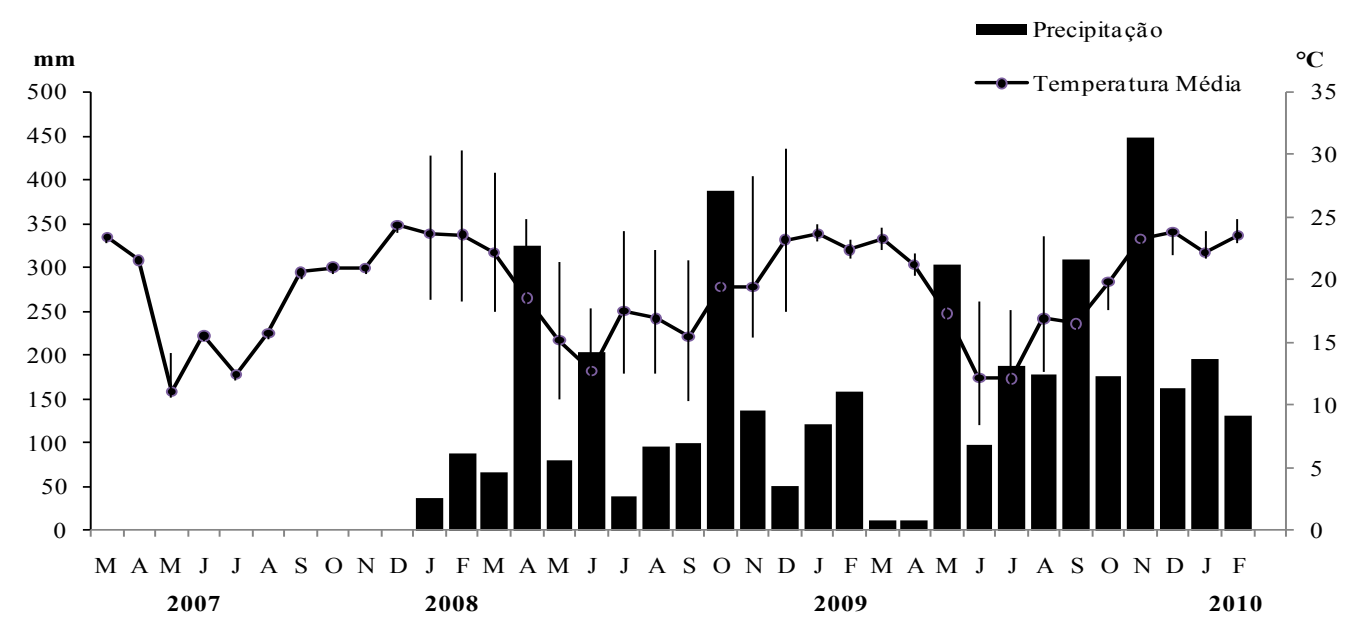

FIGURA 1: Precipitação $(\mathrm{mm})$ e temperatura $\left({ }^{\circ} \mathrm{C}\right)$ média mensal no Município de Frederico Westphalen, RS, no período de observações fenológicas (março de 2007 a março de 2010). Fonte: Estação Climatológica do CESNORS - UFSM, Frederico Westphalen, RS (linhas verticais expressam a temperatura máxima e mínima mensal).

FIGURE 1: Rainfall $(\mathrm{mm})$ and temperature $\left({ }^{\circ} \mathrm{C}\right)$ monthly average in the municipality of Frederico Westphalen, Rio Grande do Sul state (RS), phenological observations (March 2007 to March 2010). Source: Climatological Station of CESNORS - UFSM, Frederico Westphalen, RS (vertical lines express the maximum and minimum monthly temperature). 
Após a constatação da presença de evento fenológico, intensificaram-se as observações, sendo estas quinzenais, a fim de analisar os padrões de frequência de indivíduos e ocorrência de cada fenofase, conforme descrito por Newstrom et al. (1994), informações que foram comparadas às condições climáticas.

Durante as observações fenológicas foram coletados, aleatoriamente, na copa de cada árvore matriz, 10 frutos maduros e inteiros, sendo armazenados em álcool (70 \%) para posterior análise, descrição e ilustração morfológica.

Somente 10 indivíduos, das 20 árvores matrizes selecionadas, dispuseram de frutos maduros no mesmo período, sendo a coleta realizada diretamente nas árvores, no mês de janeiro de 2008, utilizando-se equipamentos como podão, escada de alumínio e cintos de segurança. Após a coleta, os frutos secos e indeiscentes foram beneficiados manualmente $\mathrm{e}$ as sementes imediatamente analisadas, separadamente, por árvore matriz.

\section{Aspectos morfológicos}

A descrição morfológica de frutos, sementes, processo germinativo, plântula e muda foi obtida por meio de observações, medições, secções transversais e longitudinais, ilustrações e fotografias realizadas dos detalhes externos e internos. A análise teve auxílio de lupa de mesa do tipo SZ40 - Olympus e paquímetro mecânico $(1 / 50 \mathrm{~mm})$.

Para a caracterização dos frutos foram utilizados 200 exemplares sadios, inteiros, sem deformação e maduros. As medidas registradas foram: comprimento, espessura e largura, considerando comprimento - a distância entre a base e o ápice do fruto, largura - o lado mais largo e espessura - o lado mais estreito. Foram observados detalhes externos e internos do pericarpo, referentes à textura, consistência, pilosidade, brilho, forma e número de sementes por fruto.

Para as medições das sementes foi utilizada a mesma metodologia estabelecida para os frutos, observando-se características externas como: cor, consistência, forma, superfície, localização e tamanho e forma da micrópila, rafe, hilo e partes associadas. Quanto às características internas foram obtidas secções transversais e longitudinais, a fim de observar a presença de endosperma, sua consistência e coloração; posição do embrião em relação ao espaço interno que ocupa dentro da semente e em relação ao tecido de reserva; forma do embrião; tamanho, posição e forma do eixo embrionário; textura, cor e forma dos cotilédones, e presença de nervuras.

Para o acompanhamento das fases de germinação e plântula foram colocadas sementes em substrato rolo de papel (umedecido com água destilada), levadas ao germinador, à temperatura de $25^{\circ} \mathrm{C}$, na presença de luz constante, sendo utilizadas duas repetições de 20 sementes cada. A germinação foi observada desde a emissão da radícula até a expansão dos protófilos, a qual foi considerada como a fase de plântula.

Para a muda, foram utilizados 50 indivíduos produzidos em casa de vegetação por semeadura direta em sacos de polietileno, sendo que, com 3 $\mathrm{mm}$ de diâmetro do colo e/ou $20 \mathrm{~cm}$ de altura, foi considerada como muda. Os elementos vegetativos observados e descritos foram: raiz (eixo principal e ramificações laterais), colo, hipocótilo, epicótilo, cotilédones, cicatrizes, protófilo e metáfilo, descrevendo a forma, número, posição, textura, consistência, pilosidade e cor destes elementos.

A metodologia e a terminologia utilizada basearam-se nos trabalhos de Roderjan (1983), Barroso et al. (1999), Vidal e Vidal (2000), Souza (2003) e Gonçalves e Lorenzi (2007).

\section{Análise de sementes}

A análise de sementes foi realizada para as diferentes matrizes, a fim de determinar o peso de mil sementes e o grau de umidade, adotandose procedimentos básicos descritos nas Regras de Análises de Sementes (BRASIL, 2009).

Para o peso de mil sementes foram utilizadas oito amostras de 100 sementes cada e verificado o coeficiente de variação. A determinação do teor de água foi obtida pelo método de estufa a $105{ }^{\circ} \mathrm{C} \pm$ $3^{\circ} \mathrm{C}$ por 24 horas.

O teste de germinação foi conduzido com oito repetições de 25 sementes, em caixa plástica (gerbox) contendo vermiculita média esterilizada, umedecida a $60 \%$ de capacidade de retenção de água. As amostras foram submetidas ao germinador, a $25{ }^{\circ} \mathrm{C} \pm 3{ }^{\circ} \mathrm{C}$, com luz branca contínua.

$\mathrm{O}$ experimento foi avaliado diariamente, avaliando o critério biológico (GUI-FERREIRA e BORGHETTI, 2004) em que as sementes são consideradas germinadas, quando apresentam emissão de radícula com, no mínimo, $2 \mathrm{~mm}$.

O teste de emergência foi realizado em casa de vegetação, conduzido em delineamento inteiramente casualizado, utilizando-se 54 tubetes em quatro repetições, sendo a semeadura realizada em tubetes $\left(175 \mathrm{~cm}^{3}\right)$ preenchidos com substrato 
MecPlant Florestal $3^{\circledR}$ à base de casca de pinus, vermiculita e adubação de base, irrigados duas vezes ao dia e avaliados diariamente. As sementes foram consideradas emergidas a partir do aparecimento do protófilo, conforme descrito por Gui-Ferreira e Borghetti (2004).

As sementes do teste de germinação e de emergência foram submetidas à assepsia utilizando hipoclorito $2 \%$ por 1 minuto e, logo após, foram lavadas em água corrente.

Foram avaliados a Porcentagem de Germinação (\%G), a Emergência (\%E), o Índice de Velocidade de Germinação (IVG) e o de Emergência (IVE) para cada matriz, conforme Gui-Ferreira e Borghetti (2004).

Os resultados primeiramente foram submetidos à análise de pressuposições básicas de normalidade e homocedasticidade (SANTANA e RANAL, 2004), utilizando os testes de ShapiroWilk e Bartlett. Quando essas pressuposições não foram atendidas, procedeu-se a transformação dos dados através do arc sen $\sqrt{x / 100}$. Para os casos não atendidos, mesmo após transformação, foi utilizado o teste não paramétrico de Kruskal-Wallis, recomendado por Santana e Ranal (2004), e após, foi aplicado o teste de Dunn, de acordo com Zar (2009), para comparações múltiplas, sendo que, as médias apresentadas nas tabelas correspondem aos dados originais. No caso do grau de umidade das sementes, foi utilizado o teste de Tukey a $5 \%$ As análises foram realizadas com o auxílio do software Statistical Analysis System (SAS) 8.2.

\section{RESULTADOS E DISCUSSÃO}

\section{Aspectos fenológicos}

Ao longo dos três anos de estudo, a partir do mês de agosto, houve o surgimento de flores junto com novas folhas, persistindo até outubro onde houve máxima taxa da fenofase (Figura 2).

Marchiori (1997) e Carvalho (2003) salientam que, no Estado do Rio Grande do Sul, a espécie floresce na primavera, o mesmo observado por Pereira et al. (2008) para o Estado do Rio de Janeiro.

O aparecimento de flores foi perceptível durante a transição para o período de maior pluviosidade na região (agosto a novembro) (Figura 1), o que pode estar relacionado à disponibilidade de água e luz. Conforme Pereira et al. (2008), esse dado pode indicar que, antes da antese, os primórdios florais se encontram em estado de latência, imposto pelo período de seca, que pode ser rompido com o aumento da umidade do ambiente.

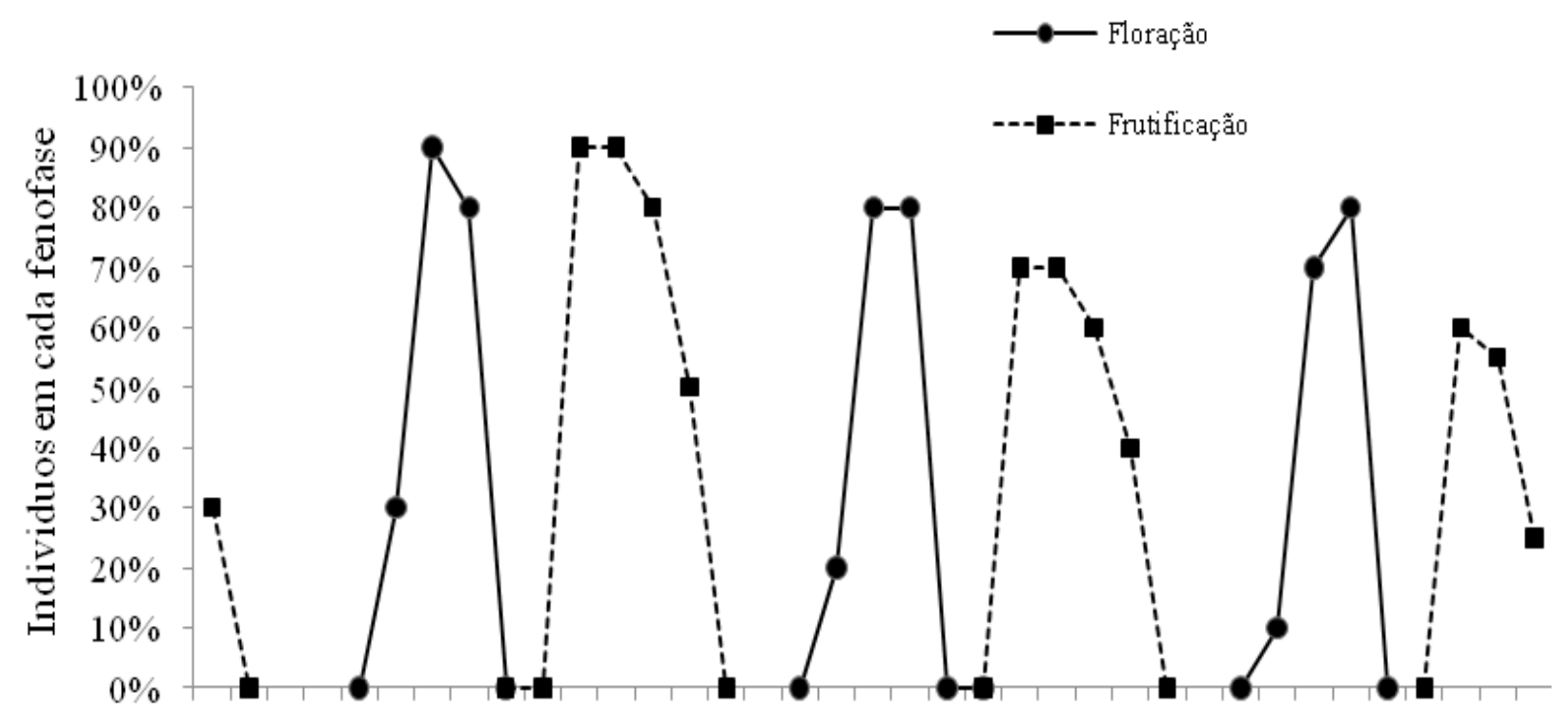

MAMJ JASOND J FMAMJ JASOND J FMAMJ JASOND J FM

2007 2008 2009

FIGURA 2: Padrão da sazonalidade da floração e frutificação de Apuleia leiocarpa (Vogel) J. F. Macbr. durante o período de março de 2007 a março de 2010 no Município de Frederico Westphalen, RS.

FIGURE 2: Pattern of seasonality of flowering and fruiting of Apuleia leiocarpa (Vogel) J. F. Macbr during the period March 2007 to March 2010 in the Municipality of Frederico Westphalen, RS. 
Segundo Morellato (1992), a temperatura e pluviometria mais elevada aumentam a decomposição da serapilheira, disponibilizando mais nutrientes, o que beneficia a fenofase durante a estação chuvosa. Concomitantemente, a variação na radiação solar, neste período, serviria como fator atuante no sincronismo do florescimento, conforme Wright e Van Schaik (1994), além do aumento de polinizadores (WIKANDER, 1984).

A ocorrência de flores foi caracterizada como anual. Pereira et al. (2008) citam a floração do tipo explosiva, de curta duração, com a presença de botões florais e, logo após, frutos. No entanto, isso somente pode ser confirmado após o estudo da biologia floral, com intervalo menor entre observações.

A maturação dos frutos ocorreu de janeiro a abril nos três anos de estudo, predominando no período de janeiro a março (Figura 2). Entretanto, alguns frutos persistiram por um período maior nas árvores, concordando com Lorenzi (2002).

Segundo Lorenzi (2002), Marchiori (1997) e Carvalho (2003), no Estado do Rio Grande do Sul, a espécie frutifica durante os meses de verão, enquanto Pereira et al. (2008) citaram que a frutificação de grápia ocorre de fevereiro a outubro no Estado do Rio de Janeiro, sendo longa e tendo dispersão anemocórica e barocórica.

Houve diferença na produção de frutos e sementes conforme o ano e árvore matriz. No ano de 2009, houve menores quantidades de frutos do que no ano anterior (2008) e posterior (2010). Esse resultado concorda parcialmente com Mattos e Guaranha (1983), os quais descreveram a espécie frutificando intensamente num período de dois ou mais anos. Já para Reitz et al. (1988), a grápia possui grande produção de frutos e sementes em todos os anos.

A irregularidade produtiva entre anos consecutivos pode estar associada a fatores genéticos e ambientais, como precipitação e temperatura, já que, no ano de 2007, a temperatura durante os meses de floração e desenvolvimento inicial dos frutos foi mais elevada, conforme visualizado na Figura 2, enquanto que, no ano de 2009, houve excesso de chuvas. Assim, temperatura e pluviometria elevadas prejudicam a formação dos frutos.

As diferenças reveladas pela comparação dos resultados obtidos, em relação a outros trabalhos com Apuleia leiocarpa, reforçam a necessidade de estudos regionais a fim de avaliar o comportamento da espécie em diferentes condições, já que, a plasticidade fenotípica é uma característica relevante a ser observada, principalmente quando se deseja coletar sementes.

De qualquer forma, observações fenológicas de cada árvore matriz, juntamente com o estudo das condições climáticas e do micro-habitat, podem auxiliar no entendimento da variação do grau de maturação em sementes de uma população de indivíduos.

De forma complementar, observou-se a senescência foliar no período de junho a setembro, comportando-se como espécie caducifólia, conforme já descrito por Marchiori (1997). Em virtude da ocorrência, neste mesmo instante, da produção de botões, abertura de flores e formação de frutos, provavelmente ocorra um desvio de recursos energéticos da fase vegetativa para a reprodutiva, como já descrito para outra espécie por Borchert et al. (2002).

\section{Aspectos morfológicos}

O fruto é simples, constituído de uma vagem (legume) oblonga ou ovado-oblonga, de coloração castanho-clara, seca e indeiscente, ápice e base agudos, superfície lisa, brilhante (Figura 3 A e B), 1 a 2 sementes transversais ao comprimento do fruto (presas internamente pelo funículo), lóculos monospérmicos e cálice persistente (Figura 3 - B), tendo dispersão anemocórica. Os caracteres assemelham-se à descrição realizada para Apuleia leiocarpa var. mollaris, descrita por Gun (1991).

De acordo com Barroso et al. (1999), o fruto tipo legume é encontrado em muitos representantes das três subfamílias Fabaceae (Leguminosae), sendo originado de ovário súpero, unicarpelar, formando duas valvas, sendo o tipo samaroide, que não possui núcleo seminífero distinto da ala, característico do gênero Apuleia.

Externamente, as sementes possuem formato elíptico, aplainado, com tegumento de coloração castanho-brilhante, às vezes mais ou menos escuro, espesso, glabro, com presença de cicatriz linear visível (hilo) localizada na região basal (Figura 3 - C), de coloração castanho-clara. De acordo com Barroso (1978), o hilo basal ocorre para as subfamílias Caesalpinioideae e Mimosideae.

Presume-se que a variação da coloração do tegumento esteja associada ao estágio de maturação das sementes em diferentes matrizes, sendo, portanto, um caractere bastante válido para identificação do momento exato para coleta. 


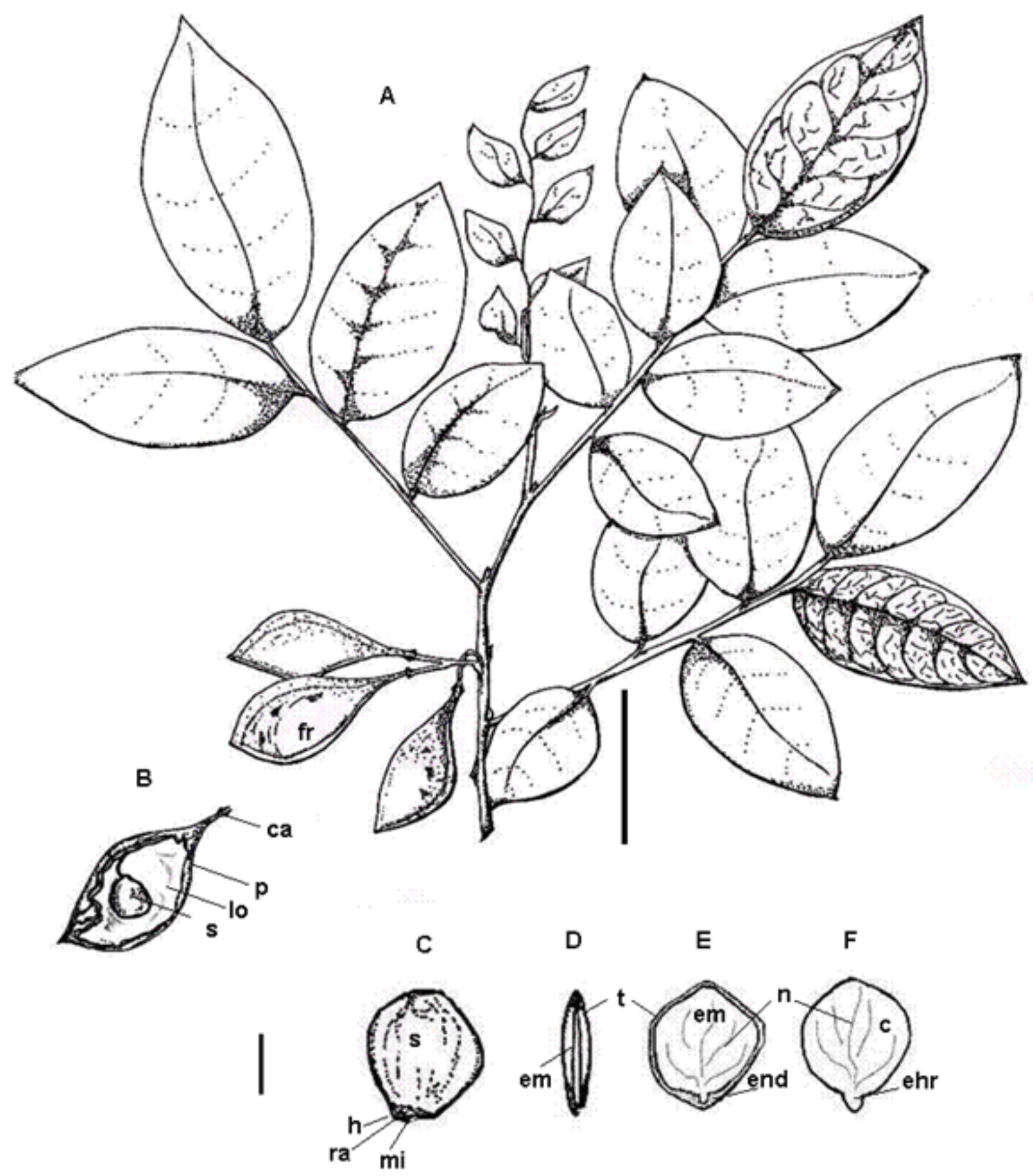

FIGURA 3: Frutos e Sementes de Apuleia leiocarpa (Vogel) J. F. Macbr.. A - Ramo com frutos maduros; B - Fruto com semente / Vista região interna; C - Semente inteira / Vista região hilar; D - Semente / Corte transversal; E - Semente / Corte longitudinal; F Embrião (c - cotilédone; ca - cálice; em - embrião; ehr - eixo hipocótilo radicular; end endosperma; $\mathrm{f}$ - fruto; $\mathrm{h}$ - hilo; lo - lóculo; mi - micrópila; $\mathrm{n}$ - nervuras; $\mathrm{p}$ - pericarpo; $\mathrm{t}$ - tegumento; ra - rafe; $\mathrm{s}$ - semente). Barra: $3,3 \mathrm{~cm}$ para A e B; $0,5 \mathrm{~cm}$ para as demais.

FIGURE 3: Fruits and Seeds Apuleia leiocarpa (Vogel) J. F. Macbr. A - Branch with ripe fruit; B fruit with seed / Vista inner region, C - entire Seed / Vista hilar region; D - Seed / cross section; E - Seed / Longitudinally; F - Embryo (c - cotyledon; ca - cup; in - embryo; EHR - hypocotyl root; end - endosperm; f - fruit; $\mathrm{h}$ - hilus; it - locule; mi - micropyle; $\mathrm{n}$ - ribs, $\mathrm{P}$ - pericarp, $\mathrm{t}$ - tegument ra - rafe; $\mathrm{s}$ - seed). Bar: $3.3 \mathrm{~cm}$ for A and B, $0.5 \mathrm{~cm}$ for the others. 
A rafe é pouco desenvolvida e a micrópila é um pequeno orifício punctiforme (poro), localizada logo abaixo do hilo (Figura $3-\mathrm{C}$ ), indicando a posição do eixo hipocótilo radicular, informação de suma importância em testes laboratoriais, impedindo, assim, o comprometimento de alguma região do embrião.

Internamente, a semente albuminada possui endosperma uniforme de coloração branco-cristalina, aderido ao tegumento e circundando o embrião, o qual ocupa $3 / 4$ do espaço interno da semente, sendo classificado como axial, espatulado, invaginado, com cotilédones foliáceos, grandes, de coloração verde, superfície lisa, nervuras visíveis, com eixo hipocótilo radicular curto, cilíndrico e espesso, de coloração amarelo-esverdeada (Figura 3 - C a F), com a presença de plúmula rudimentar.

A presença do endosperma circundando o embrião está descrita para, aproximadamente, $32 \%$ da Caesalpinioideae (GUNN, 1991).

As dimensões de frutos e sementes tiveram ampla variação, sendo que os frutos variaram de 1,45 a $3,01 \mathrm{~cm}$ de comprimento, 1,20 a $2,07 \mathrm{~cm}$ de largura e 0,2 a $0,3 \mathrm{~cm}$ de espessura, enquanto que as sementes tiveram 1,2 a $2,1 \mathrm{~cm}, 0,6$ a $0,95 \mathrm{~cm}$ e 0,1 a $0,2 \mathrm{~cm}$, respectivamente (Tabela 1 ).

Reitz et al. (1988) descreveram frutos de 4 a $7 \mathrm{~cm}$ de comprimento e 2 a 2,5 cm de largura. Já Loureiro et al. (2004), 4 a 5,8 cm de comprimento e 1,65 a $2 \mathrm{~cm}$ de largura, no entanto, não citam se as descrições correspondem à espécie Apuleia leiocarpa var. leiocarpa ou mollaris.

A variação quanto ao tamanho, provavelmente, acontece em função da variabilidade genética entre matrizes e a influência ambiental durante seu desenvolvimento. Assim, o tamanho de frutos e sementes pode variar entre plantas da mesma espécie, entre anos reprodutivos e também na mesma planta, como já relatado por Piña-Rodrigues e Aguiar (1993).

A diferença no tamanho tanto de frutos quanto de sementes entre indivíduos, numa mesma população, possibilita a seleção com vistas à melhoria de um dado caractere, constituindo-se numa das mais importantes fontes de variabilidade disponíveis (SANTOS et al., 2009), também auxiliando no estudo da dispersão e agentes dispersores.

A germinação foi classificada como epígea e as plântulas são do tipo fanerocotiledonar com emergência curvada, embora os cotilédones possam permanecer parcialmente envolvidos pelo tegumento seminal. As fases podem ser visualizadas na Figura 4.

Inicialmente há hidratação da semente, a qual intumesce, aumentando seu volume; posteriormente, entre o $2^{\circ}$ e $5^{\circ}$ dia, emite a radícula, próxima ao hilo (Figura 4 - A). A raiz primária cilíndrica, esbranquiçada, rapidamente desenvolvese, engrossando e sofrendo afinamento com dilatação na base. À medida que a raiz se alonga, adquire a coloração amarela. Uma leve dilatação da extremidade apical da radícula marca o início da coifa, que é glabra, cilíndrica, alongada e termina numa ponta aguda (Figura $4-\mathrm{C}$ a H), de coloração amarelo-acastanhada.

O colo é curto, cilíndrico e esbranquiçado, delimitado por um leve alargamento do hipocótilo, inicialmente curvo, tornando-se reto à medida que ocorre o seu alongamento (Figura $4-\mathrm{E}$ a G). O hipocótilo é herbáceo, de coloração verde-clara, elevando os cotilédones envolvidos pelo tegumento acima do solo (Figura $4-\mathrm{B}$ a E). O tegumento se desprende dos cotilédones 5 a 7 dias após a germinação (Figura $4-\mathrm{E}$ ), quando os cotilédones iniciam a abertura horizontal, sendo estes, foliáceocoriáceos, opostos, oblongos, com ápice obtuso ou

TABELA 1: Biometria de frutos e sementes de 10 matrizes de Apuleia leiocarpa (Vogel) J. F. Macbr., Frederico Westphalen, RS, janeiro de 2008.

TABLE 1: Biometry of fruits and seeds of 10 matrix Apuleia leiocarpa (Vogel) J. F. Macbr., Frederico Westphalen, RS, January 2008.

\begin{tabular}{ccccccc}
\hline \multirow{2}{*}{ Frutos } & $\begin{array}{c}\text { Mínima } \\
(\mathrm{cm})\end{array}$ & $\begin{array}{c}\text { Máxima } \\
(\mathrm{cm})\end{array}$ & $\begin{array}{c}\text { Média } \\
(\mathrm{cm})\end{array}$ & $\begin{array}{c}\text { Desvio } \\
\text { Padrão }\end{array}$ & $\begin{array}{c}\text { CV } \\
(\%)\end{array}$ \\
\hline \multirow{5}{*}{ Sementes } & Comprimento & 1,45 & 3,01 & 2,05 & 0,05 & 16,34 \\
& Largura & 1,20 & 2,07 & 1,77 & 0,04 & 15,42 \\
& Espessura & 0,20 & 0,30 & 0,25 & 0,04 & 12,46 \\
\cline { 2 - 7 } & Comprimento & 1,2 & 2,1 & 1,67 & 0,08 & 11,56 \\
& Largura & 0,6 & 0,95 & 0,79 & 0,06 & 10,13 \\
& Espessura & 0,1 & 0,2 & 0,1 & 0,05 & 9,41 \\
\hline
\end{tabular}


arredondado, base levemente truncada, borda inteira, nervuras evidentes (Figura $4-\mathrm{F}$ ), de coloração verde-clara, tornando-se mais escura ao passar dos dias.

Entre o $7^{\circ}$ e $8^{\circ}$ dia após a germinação, visualiza-se entre os cotilédones o primeiro protófilo de coloração verde-clara (Figura $4-\mathrm{C}$ ) e ao $25^{\circ}$ dia a plântula está completamente formada, com raiz pivotante de coloração verde-clara de 5 a $7 \mathrm{~cm}$ de comprimento e raízes secundárias finas (Figura $4-\mathrm{G}$ e H). O hipocótilo é de formato cilíndrico, estriado, glabro, 8 a $10 \mathrm{~cm}$ de comprimento, com coloração verde-amarelada na base e verde-clara no ápice (Figura 4 - H) e o epicótilo, também cilíndrico, possui coloração verde-clara brilhante, medindo em torno de 2,5 cm de comprimento (Figura 4-G; H).

Os cotilédones são persistentes, de 1,5 a $2 \mathrm{~cm}$ de comprimento e 1 a $1,3 \mathrm{~cm}$ de largura. $\mathrm{O}$ protófilo é simples, alterno, peciolado, forma ovada, elíptica, de ápice arredondado, base arredondada ou obtusa e bordos inteiros (Figura 4 - H). As plântulas possuem um rápido desenvolvimento do epicótilo e um acelerado processo de formação e expansão de novas folhas.

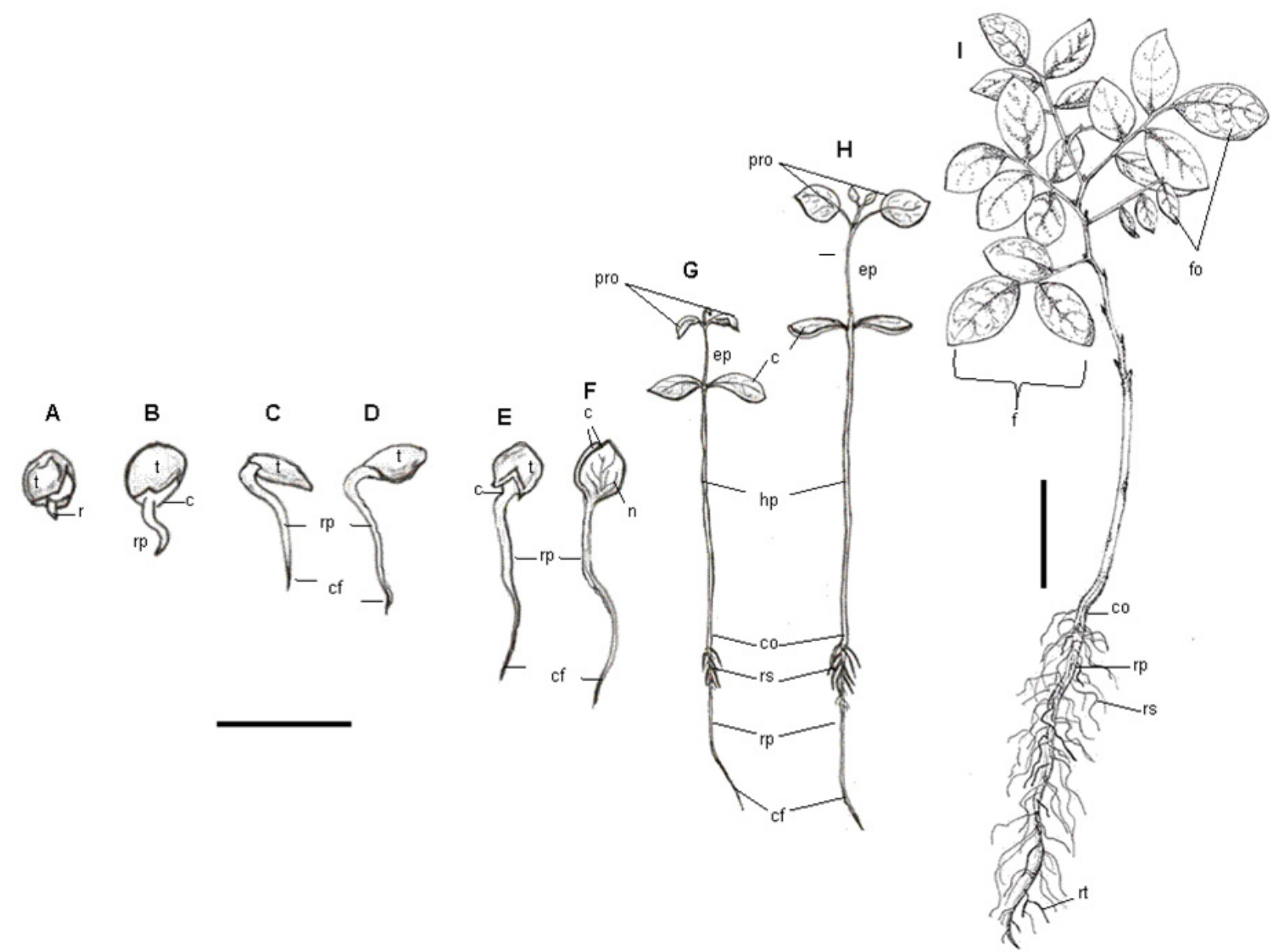

FIGURA 4: Estágios sucessivos da germinação de Apuleia leiocarpa (Vogel) J. F. Macbr., plântula e muda. A - Emissão da radícula; $\mathrm{B}, \mathrm{C}$ e $\mathrm{D}-3^{\circ}, 4^{\circ}$ e $5^{\circ}$ dia após a semeadura, respectivamente; E - Perda do tegumento; F - Abertura dos cotilédones entre o $5^{\circ}$ e $7^{\circ}$ dia de semeadura; $\mathrm{G}$ e H - Plântula; I - Muda (c - cotilédone; cf - coifa; co - colo; ep - epicótilo; f - folha; fo folíolo; hp - hipocótilo; $\mathrm{n}$ - nervuras; pro - protófilo; $\mathrm{r}$ - radícula; $\mathrm{rp}$ - raiz primária; $\mathrm{rs}$ - raiz secundária; $\mathrm{rt}$ - raiz terciária; $\mathrm{t}$ - tegumento). Barra: $4 \mathrm{~cm}$ para $\mathrm{A}$ a $\mathrm{H} \mathrm{e} 5 \mathrm{~cm}$ para I.

FIGURE 4: Stages of successive Apuleia leiocarpa (Vogel) J. F. Macbr. germination, plantlent and seedling. A - Issue radicle, B, C and D - 3rd, 4th and 5th day after sowing, respectively; E - Loss of integument; F - Opening of the cotyledons between the 5th and 7th day of sowing, $\mathrm{G}$ and $\mathrm{H}-$ Plantlent; I - Seedling (c - cotyledon; cf - hood; co - colon; ep - epicotyl f - leaf; fo - leaflet; $\mathrm{hp}$ - hypocotyl; $\mathrm{n}$ - ribs; pro - foliage leaf; $\mathrm{r}$ - radicle; rp - primary root; rs - secondary root; $\mathrm{rt}$ - root tertiary, $\mathrm{t}$ - tegument). Bar: $4 \mathrm{~cm}$ for the $\mathrm{H}$ and $5 \mathrm{~cm} \mathrm{I}$. 
Quanto à muda, quatro meses após a germinação, possui altura média de $18 \mathrm{~cm}$ e diâmetro do colo em torno de $3 \mathrm{~mm}$. O sistema radicular é pivotante, raiz axial cilíndrica e fibrosa, afinando gradualmente em direção à porção terminal, sendo de superfície glabra e coloração amarelo-esverdeada. As raízes laterais são cilíndricas, glabras, finas, distribuídas em toda a extensão da raiz principal (Figura 4 - I).

O colo é cilíndrico (Figura $4-$ I) e o caule jovem possui entrenós de consistência subherbácea, com superfície de coloração verde-clara brilhante e lisa. As folhas são compostas, pecioladas, alternas, imparipenadas, base foliar arredondada ou obtusa, ápice acuminado, margem inteira, forma variável, de ovais a oval-lanceoladas, de elípticas a ovadoblongas (Figura $4-\mathrm{I}$ ).

Os folíolos são peciolados, limbo oblongo, base arredondada, aguda, obtusa, ápice obtuso ou arredondado, bordos inteiros (Figura 4 - I) e nervação broquidódroma. Essa descrição é semelhante à realizada por Marchiori (1997), para a fase adulta da espécie.

Não foram encontrados estudos envolvendo a caracterização e ilustração morfológica do processo germinativo até a fase de muda para grápia. Assim, os resultados aqui encontrados poderão auxiliar trabalhos laboratoriais e a campo, como identificação da germinação em análise de sementes e estudos de regeneração.

\section{Análise de sementes}

A análise estatística para o número de sementes por quilograma, porcentagem de umidade, germinação e emergência, índice de velocidade de germinação e emergência indicou diferença entre as matrizes observadas (Tabela 2), podendo-se inferir associação a efeitos genéticos e microambientais.

$\mathrm{O}$ número de sementes por quilograma apresentou média de 10.027 unidades (Tabela 2), com o coeficiente de variação menor de $4 \%$, descrito como apropriado para espécies não palhentas (BRASIL, 2009), o que indica pouca variação do material obtido em cada matriz.

Os valores obtidos foram expressivamente inferiores aos apresentados por Loureiro et al. (2004) que constataram 17.082 unidades com umidade inicial de $14 \%$, sugerindo que as sementes coletadas para este estudo são de maior tamanho, provavelmente devido às características genéticas das árvores matrizes, ou até mesmo às condições ambientais durante o desenvolvimento das sementes.
Ledo et al. (2002) sugeriram que o tamanho de sementes está relacionado à quantidade de reservas, influenciando a germinação e emergência. No mesmo sentido, Pedron et al. (2004) destacaram que a classificação de sementes por peso e tamanho visa à uniformidade de emergência das plântulas. No entanto, neste estudo, aparentemente não houve influência do tamanho e do peso das sementes obtidos através da quantidade de sementes por quilograma, no vigor das plântulas. Porém, há necessidade de se classificar sementes de uma mesma matriz por peso e tamanho, além de analisar seu comportamento germinativo para averiguar se há ou não influência.

$\mathrm{O}$ teor inicial de água nas sementes das diferentes matrizes variou de 12 a $28 \%$ (Tabela 2), mas não permitiu relacionar a umidade com a porcentagem de germinação. Porém, este parâmetro é de suma importância, estando associado à qualidade fisiológica das sementes, podendo favorecer a germinação, além de ser um dos principais indicadores do melhor período de coleta e armazenamento de sementes de diferentes espécies, como já descrito por Ferreira et al. (2001).

Observou-se diferença significativa entre as árvores matrizes, para todas as variáveis analisadas. Conforme visualizado na Figura 5, o processo germinativo iniciou após o $7^{\circ}$ dia de semeadura, estendendo-se até o $160^{\circ}$ dia, variando de 13 a $96 \%$ de sementes germinadas (Figura 5, Tabela 2) sem a realização de testes de quebra de dormência. Este resultado sugere que a matriz pode estar influenciando, seja através do estado nutricional da planta e/ou pelo estágio de maturação das sementes.

Presume-se que, a partir da informação de que a dormência exógena pode ser primária ou secundária, conforme destacaram Gui-Ferreira e Borghetti (2004), o diferente grau de maturação das sementes pode ser determinante para a ocorrência da dormência tegumentar secundária, não havendo, portanto, uniformidade do lote quando as sementes são coletadas de matrizes com diferentes graus de maturidade.

De acordo com Gui-Ferreira e Borghetti (2004), sementes que desenvolvem tegumentos impermeáveis são capazes de embeber e germinar quando coletadas no ponto de maturidade fisiológica, antes do início da fase de dessecamento.

Essa é uma das possibilidades para se explicar os diferentes índices de germinação das sementes de grápia, provenientes de diferentes matrizes como neste trabalho, ou do lote de 
sementes, conforme Magalhães et al. (1985), que, sem a superação da dormência, obtiveram $29,7 \%$ de germinação. Já Nicoloso et al. (1997) obtiveram $9,40 \%$ de índice germinativo no $5^{\circ}$ dia, e $32,12 \%$ ao $70^{\circ}$ dia.

Segundo Carvalho (2003), a germinação tem início entre $10^{\circ}$ e $30^{\circ}$ dia após a semeadura, levando até 80 dias para germinar sem tratamento pré-germinativo adequado. Nicoloso et al. (1997) descreveram que a espécie apresenta germinação difícil e irregular, podendo levar até 50 dias para emergir.

Os resultados obtidos neste trabalho, comparados a outros estudos, sugerem que a potencialidade de germinação, assim como vigor, estejam associados às árvores matrizes individualmente e que a superação da dormência silvicultural é importante para a homogeneização da germinação, principalmente para a produção de mudas provenientes de um lote de várias matrizes.

Analisando a matriz 245, na Figura 9, observou-se que esta teve cerca de $50 \%$ das sementes germinadas aos 20 dias, no entanto, a matriz 268, no mesmo período, teve $5 \%$ de germinação.

De acordo com a Figura 6, a emergência teve início a partir do $12^{\circ}$ dia após a semeadura, estendeu-se até o $80^{\circ}$ dia, estabilizando-se após esse período. A porcentagem final de sementes emergidas variou de 26,38 a 87,54 (Figura 6, Tabela 2), sendo que, assim como na germinação, o índice de emergência da matriz 245 foi mais elevado, sobressaindo-se em relação às outras matrizes.

TABELA 2: Número de sementes viáveis por quilograma $(\mathrm{Kg})$ e Coeficiente de Variação (CV\%), Porcentagem de Umidade (\%U), de Germinação (\%G), de Emergência (\%E) e Índice de Velocidade de Germinação (IVG) e Índice de Velocidade de Emergência (IVE) de sementes de diferentes matrizes de Apuleia leiocarpa (Vogel) J. F. Macbr., Frederico Westphalen, RS, janeiro de 2008.

TABLE 2: Number of seeds viable per kilogram $(\mathrm{kg})$ and Coefficient of Variation (CV\%), Percentage of Moisture (\% U) Germination (\% G), Emergency (E\%) and Germination Speed Index (GSI) and Emergency Speed Index (EVI) of seeds of different matrices Apuleia leiocarpa (Vogel) J. F. Macbr., Frederico Westphalen, RS, January 2008.

\begin{tabular}{|c|c|c|c|c|c|c|}
\hline $\begin{array}{l}\text { Árvore } \\
\text { Matriz }\end{array}$ & $\begin{array}{c}\mathrm{N}^{\circ} \text { de } \\
\text { sementes por } \\
\mathrm{Kg} / \mathrm{CV} \%\end{array}$ & $\% \mathrm{U}^{2}$ & $\% \mathrm{G}^{3}$ & $\mathrm{IVG}^{3}$ & $\% \mathrm{E}^{3}$ & $\mathrm{IVE}^{3}$ \\
\hline 245 & $9.908 / 3,57$ & $17,28 \mathrm{bc}$ & 96 a & $4,96 \mathrm{c}$ & $87,54 \mathrm{a}$ & $9,89 \mathrm{a}$ \\
\hline 249 & $11.197 / 5,25$ & $24,24 \mathrm{ab}$ & $95 \mathrm{a}$ & $3,93 \mathrm{~d}$ & 86,83 a & $6,99 \mathrm{c}$ \\
\hline 270 & $8.715 / 4,78$ & $17,48 \mathrm{bc}$ & $89 a$ & $3,89 \mathrm{a}$ & 79,17 a & $8,57 \mathrm{~b}$ \\
\hline 248 & $10.471 / 2,45$ & 27,97 a & $83 \mathrm{a}$ & $2,97 \mathrm{~b}$ & $69,83 \mathrm{ab}$ & $5,67 \mathrm{~d}$ \\
\hline 242 & $9.943 / 4,65$ & $25,72 \mathrm{ab}$ & $66 \mathrm{~b}$ & $2,25 \mathrm{e}$ & $68,08 \mathrm{ab}$ & $5,22 \mathrm{e}$ \\
\hline 278 & $8.570 / 5,24$ & $19,62 \mathrm{abc}$ & $62 \mathrm{~b}$ & $2,06 \mathrm{e}$ & $64,75 \mathrm{ab}$ & $3,43 \mathrm{f}$ \\
\hline 268 & $10.040 / 2,17$ & $12,43 \mathrm{c}$ & $29 \mathrm{c}$ & $0,96 \mathrm{f}$ & $44,38 \mathrm{~b}$ & $3,23 \mathrm{~g}$ \\
\hline 257 & $10.190 / 3,49$ & $14,50 \mathrm{c}$ & $17 \mathrm{c}$ & $0,70 \mathrm{fg}$ & $27,00 \mathrm{~b}$ & $1,46 \mathrm{~h}$ \\
\hline 243 & $10.805 / 3,78$ & $27,50 \mathrm{a}$ & $16 \mathrm{c}$ & $0,51 \mathrm{~g}$ & $30,53 \mathrm{~b}$ & $1,74 \mathrm{~h}$ \\
\hline 274 & $10.431 / 3,11$ & $24,71 \mathrm{ab}$ & $13 \mathrm{c}$ & $0,39 \mathrm{~g}$ & $26,38 \mathrm{~b}$ & $2,24 \mathrm{~h}$ \\
\hline \multicolumn{2}{|c|}{$\begin{array}{l}\text { Pressuposições }{ }^{1} \mathrm{~W} \\
\text { Básicas } \chi^{2} \\
\mathrm{CV} \%\end{array}$} & $\begin{array}{c}\mathbf{P r}<W \text { 0,419 } \\
\text { Alpha 0,783 } \\
10,645\end{array}$ & $\begin{array}{c}\mathrm{Pr}<\mathrm{W} 0,003 / 0.003 \\
\text { Alpha 0,761 } \\
8,541\end{array}$ & $\begin{array}{c}\mathrm{Pr}<\mathrm{W} 0,001 / 0,003 \\
\text { Alpha } 0,002 / 0,016 \\
4,095\end{array}$ & $\begin{array}{c}\mathrm{Pr}<\mathrm{W} 0,044 / 0,015 \\
\text { Alpha 0,694 } \\
18,387\end{array}$ & $\begin{array}{c}\mathrm{Pr}<\mathrm{W} 0,002 / 0,010 \\
\text { Alpha 1,299 } \\
1,731\end{array}$ \\
\hline
\end{tabular}

Em que: ${ }^{1} \mathrm{~W}$ : estatística do teste de Shapiro-Wilk e $\chi^{2}$ : estatística do teste de Bartlett. Valores em negrito indicam normalidade dos resíduos e homogeneidade da variância, respectivamente, após transformação dos dados. As médias seguidas da mesma letra na coluna não diferem entre si pelo teste de ${ }^{2}$ Tukey, ${ }^{3}$ Kruskal-Wallis e ${ }^{3}$ Dunn a $5 \%$ de probabilidade de erro. 


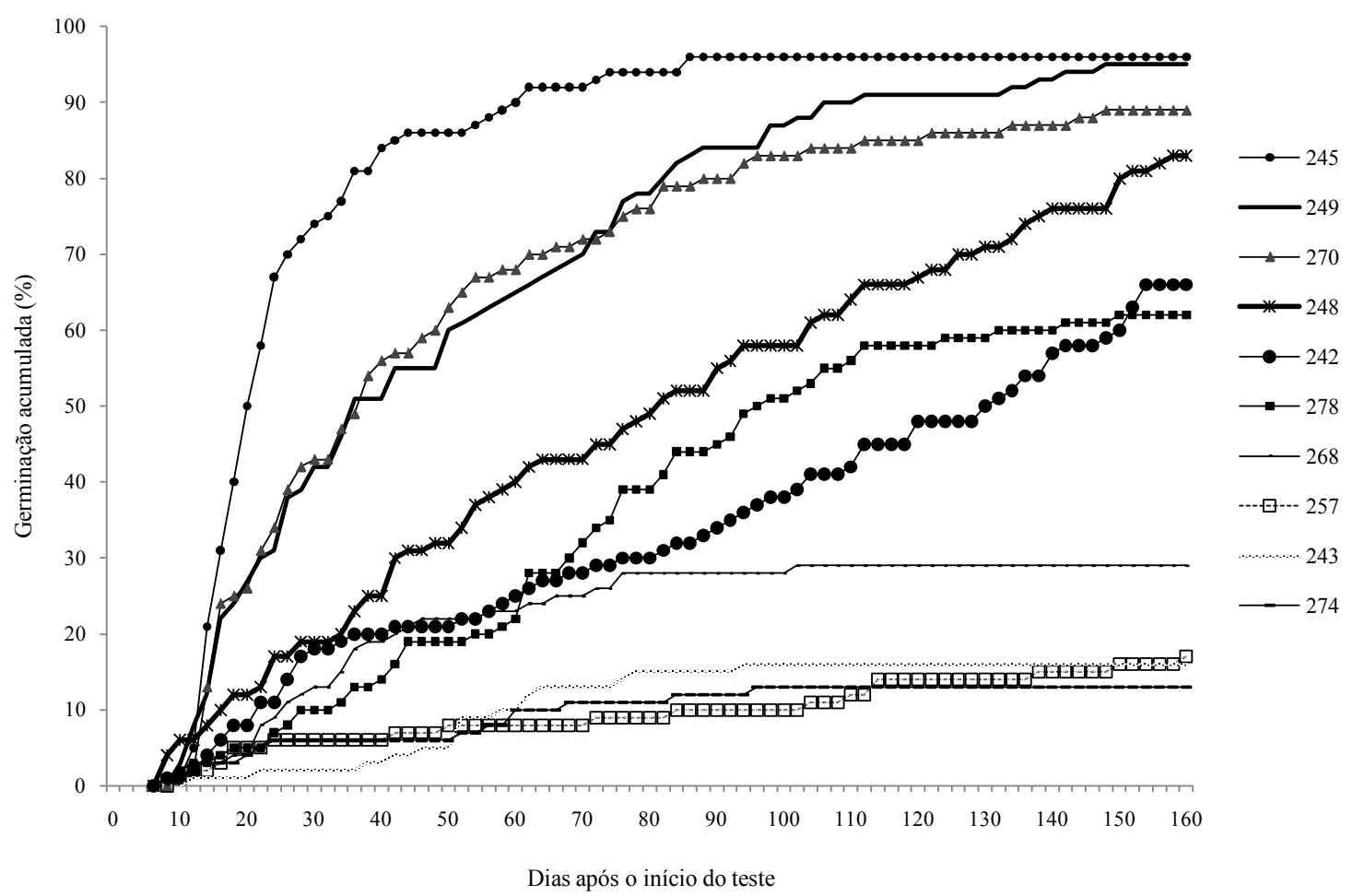

FIGURA 5: Germinação cumulativa de sementes de Apuleia leiocarpa (Vogel) J. F. Macbr., provenientes de diferentes matrizes, Frederico Westphalen, RS, janeiro de 2008.

FIGURE 5: Cumulative germination of seeds of Apuleia leiocarpa (Vogel) J. F. Macbr. from different matrices, Frederico Westphalen, RS, January 2008.

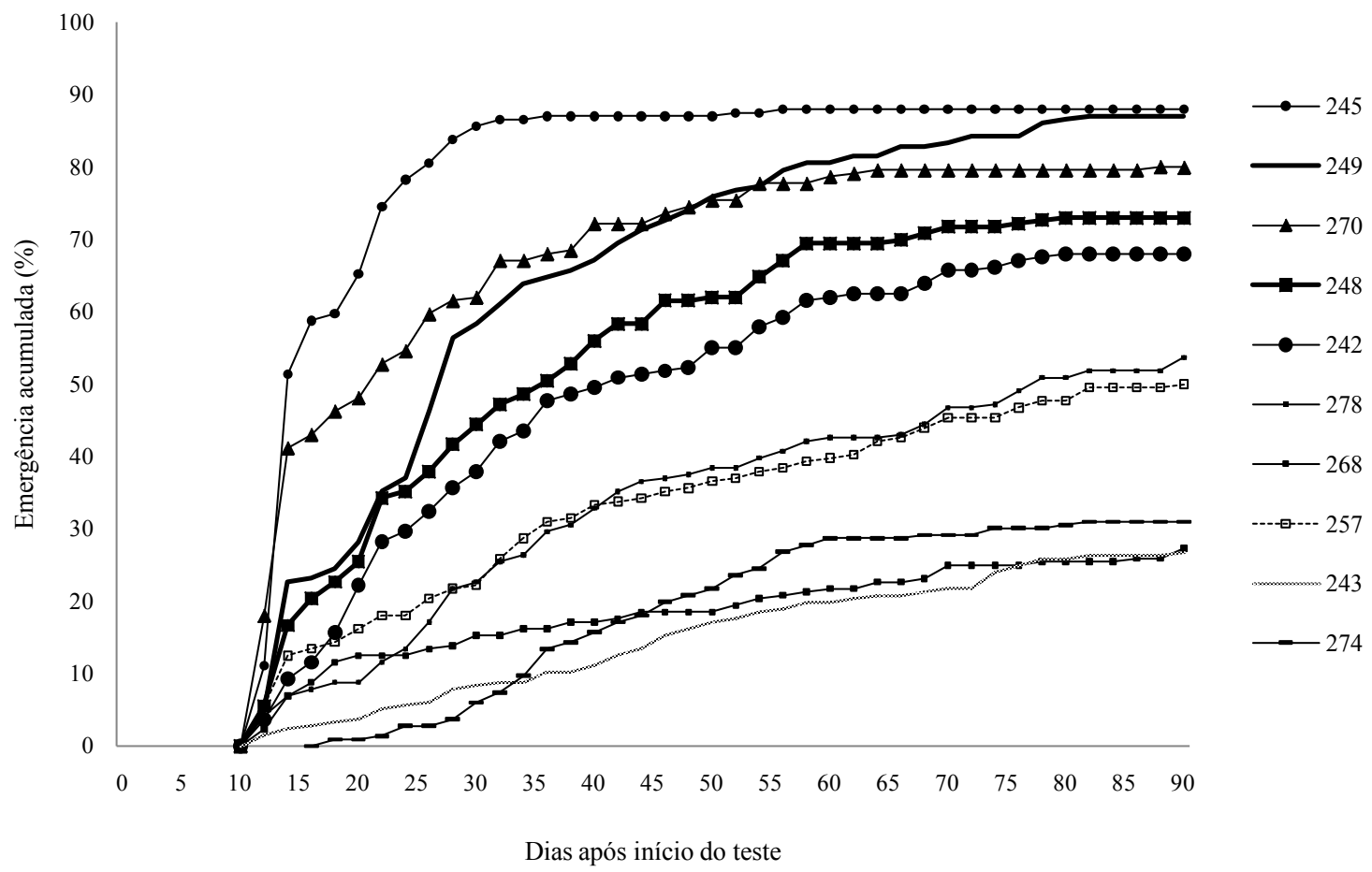

FIGURA 6: Emergência cumulativa de sementes de Apuleia leiocarpa (Vogel) J. F. Macbr., provenientes de diferentes matrizes, Frederico Westphalen, RS, janeiro de 2008.

FIGURE 6: Emergency cumulative seed Apuleia leiocarpa (Vogel) J. F. Macbr. from different matrices, Frederico Westphalen, RS, January 2008. 
Como visualizado na Tabela 2, Figuras 5 e 6 , tanto em testes laboratoriais quanto em viveiro, houve diferenças significativas entre matrizes, considerando-se todas as variáveis estudadas. As diferenças observadas no número de sementes germinadas eemergidas transcenderamnavelocidade de germinação e emergência. Assim, pressupõese que os indivíduos que obtiveram os maiores índices para germinação e emergência $(245,249$, 270 e 248) possuem características determinantes, sejam elas genéticas, fenotípicas, ou oriundas do micro-habitat, o que influenciaria positivamente o lote de sementes, se este fosse formado. Entretanto, os indivíduos que não apresentaram resultados satisfatórios comprometeriam a qualidade do lote de sementes.

Tal situação remete para a viabilidade econômica de coletar sementes em árvores selecionadas, a partir de características morfológicas, distância e número mínimo de árvores matrizes, considerando a fragmentação e restrições legais e práticas.

As dificuldades, quanto à coleta de sementes de espécies nativas de grande porte, como a grápia, a menor produção de sementes se comparada com árvores isoladas e uma considerável quantidade de sementes atacadas por predadores naturais, ressaltam propostas como a de Higa e Silva (2006), que sugerem a implantação de pomares de sementes de espécies florestais nativas, com a finalidade de aumentar a oferta de sementes de qualidade física e fisiológica para restauração ambiental.

\section{CONCLUSÕES}

Estudos referentes à biologia floral de Apuleia leiocarpa (Vogel) J. F. Macbr. podem ser realizados de agosto a outubro, havendo maior presença de flores de setembro a outubro. Além do mais, a coleta de sementes dessa espécie pode ser realizada entre janeiro e abril, havendo concentração de frutos maduros de janeiro a março.

Durante o período de um ano, dos três anos de observações, um número menor de indivíduos apresentou as fenofases estudadas, como também, nos três anos, houve irregularidade entre árvores matrizes quanto à produção e maturação de frutos, prejudicando a coleta de sementes a partir de um número maior de indivíduos.

O reconhecimento taxonômico da espécie é possível através dos caracteres morfológicos, tais como, o tipo de fruto, o qual é simples, seco e indeiscente, a semente albuminosa, de coloração castanha, com tegumento rígido, assim como, a germinação epígea e a plântula do tipo fanerocotiledonar.

A diferença observada nos testes físicos, de germinação e de emergência de sementes entre matrizes, influi na qualidade do lote de sementes.

A mistura de sementes obtidas de diferentes árvores matrizes selecionadas, de forma equitativa, proporciona uma estimativa quanto ao comportamento médio da população estudada; no entanto, pode comprometer o resultado final quanto ao vigor das plântulas, em função do diferente período de maturação das sementes, características fenotípicas dos indivíduos arbóreos, ou a influência do micro-habitat.

\section{REFERÊNCIAS BIBLIOGRÁFICAS}

BARROSO, G. M. et al. Frutos e Sementes: morfologia aplicada à sistemática de dicotiledôneas. Viçosa: Universidade Federal de Viçosa, 1999. $443 \mathrm{p}$.

BARROSO, G. M. Sistemática de Angiospermas do Brasil. São Paulo: EDUSP, 1978. 255 p. v. 1. BORCHERT, R.; RIVERA, G.; HAGNAUER, W. Modification of vegetative phenology in a tropical semi-deciduous forest by abnormal drought and rain. Biotropica, St. Louis, v. 34, n. 1, p. 27-39, 2002.

BRASIL. Ministério da Agricultura, Pecuária e Abastecimento. Secretaria de Defesa Agropecuária. Regras para análises de sementes. Brasília: Mapa/ ACS, 2009. 399 p.

CARVALHO, P. E. R. Espécies arbóreas brasileiras. Colombo: EMBRAPA/CNPR, Brasília: EMBRAPA-SPI, 2003. 1039 p. v.1.

CORREIA, M. C. R.; PINHEIRO, M. C. B.; LIMA, H. A. de. Produção de frutos e germinação de sementes de Amemopaegma chamberlaynii Bur. \& K. Schum. (Bignoniaceae) - Um registro de poliembrionia. Sitientibus Série Ciências Biológicas, Feira de Santana, v. 5, n. 2, p. 68-71, 2005.

CUNHA, A. O. et al. Efeitos de substratos e das dimensões dos recipientes na qualidade das mudas de Tabebuia impetiginosa (Mart. ex Dc.) Standl. Revista Árvore, Viçosa, v. 29, n. 4, p. 507-516, 2005.

FERREIRA, R. A.; DAVIDE, A. C.; TONETTI, O. A. Morfologia de sementes e plântulas de pauterra (Qualea grandilfora - Vochysiaceae). Revista 
Brasileira de Sementes, Londrina, v. 23, n. 1, p. 116-122, 2001.

FOURNIER, L. A. Un método cuantitativo para la medición de características fenológicas en árboles. Turrialba, San José, Costa Rica, v. 24, n. 4, p. 422423, 1974.

GONÇALVES, E. G.; LORENZI, H. Morfologia Vegetal: Organografia e Dicionário Ilustrado de Morfologia das Plantas Vasculares. São Paulo: Instituto Plantarum de Estudos da Flora, 2007. $416 \mathrm{p}$.

GUI-FERREIRA, A.; BORGHETTI, F. Germinação: do básico ao aplicado. Porto Alegre: Artmed, 2004. 323 p.

GUNN, C. R. Fruits and seeds of genera in the subfamily Caesalpinioideae (Fabaceae). United States Department of Agriculture, 1991. 408 p.( Technical Bulletin 1755, v. 1).

HIGA, A. R.; SILVA, L. D. Pomar de Sementes de Espécies Florestais Nativas. Curitiba: FUPEF, 2006. v. 1.264 p.

LEDO, A. S. et al. Efeito do tamanho da semente, do substrato e pré-embebição na germinação de sementes de pupunha. Revista Ciência Agronômica, Fortaleza, v. 33, n. 1, p. 29-32, 2002. LORENZI, H. Árvores brasileiras: manual de identificação e cultivo de plantas arbóreas nativas do Brasil. Nova Odessa: Plantarum, 1992. 352 p.

LOUREIRO, M. B.; GONÇALVES, E. R. da.; ROSSETTO, C. A. V. Avaliação do efeito do tamanho de sementes na germinacao e no vigor de garapa (Apuleia leiocarpa (Vog.) MACBR. Revista Univ. Rural. Seropédica, v. 24, n. 1, p. 73-77 janjun. 2004. (Ser. Ci. Vida).

MAGALHÃES, L. M. S. et al. Relatório final de projeto de preservação do germoplasma do reservatório da UHE - Tucuruí. Manaus: Convênio Eletronorte/ CNPq/ INPA, Manaus, 1985. 53p.

MARCHIORI, J. N. C. Dendrologia das angiospermas: leguminosas. Santa Maria: Ed. UFSM, 1997. $200 \mathrm{p}$.

MATTOS, N. F., GUARANHA, J. Contribuições ao estudo da Grápia. Porto Alegre: Boletim do Instituto de Pesquisa de Recursos Naturais Renováveis, 1983. 27 p.

MORELLATO, L. P. C. et al. Estudo comparativo da fenologia de espécies arbóreas de floresta de altitude e floresta mesófila semi-decidua na Serra do Japi, Jundiaí, São Paulo. Revista Brasileira de Botânica, São Paulo, v.12, p. 85-98, 1989.

MORELLATO, L. P. Sazonalidade e dinâmica de ecossistemas florestais na Serra do Japi. In: MORELLATO, L. P. (Ed.). História natural da Serra do Japi: ecologia e preservação de uma área florestal no sudeste do Brasil. Campinas: Ed. da UNICAMP, 1992, p. 97-110.

MORI, E. S. Genética de populações arbóreas: orientações básicas para seleção e marcação de matrizes. IF Sér. Reg. São Paulo, n. 5. p. 35-44, ago. 2003.

NEWSTROM, L. E.; FRANKIE, G. W.; BAKER, H. G. A new classification for plant phenology based on flowering patterns in lowland tropical rain forest trees at La Selva, Costa Rica. Biotrópica, St. Louis, v. 26, p. 141-159, 1994.

NICOLOSO, F. T. et al. Efeito de métodos de escarificação na superação da dormência de sementes e de substratos na germinação e no desenvolvimento da grápia (Apuleia leiocarpa). Ciencia Rural, Santa Maria, v. 27, n. 3, p. 419-424, 1997.

PEDRON, F. A.; MENEZES, J. P.; MENEZES, N. L. Parâmetros biométricos de fruto, endocarpo e semente de butiazeiro. Ciência Rural, Santa Maria, v. 34, n. 2, p. $585-586,2004$.

PEREIRA, T. S. et al. Fenologia de espécies arbóreas em Floresta Atlântica da Reserva Biológica de Poço das Antas, Rio de Janeiro, Brasil. Iheringia, Serie Botânica, Porto Alegre, v. 63, n. 2, p. 329-339, jul/ dez. 2008.

PIÑA-RODRIGUES, F. C. M.; AGUIAR, I. B. Maturação e dispersão de sementes. In: AGUIAR, I. B.; PIÑA-RODRIGUES, F. C. M.; FIGLIOLIA, M. B (Eds.). Sementes florestais tropicais. Brasília: ABRATES, 1993. p. 215-274.

PIÑA-RODRIGUES, F. C. M.; FREIRE, J. M.; SILVA, L. D. Parâmetros genéticos para colheita de sementes de espécies florestais. In: PIÑARODRIGUES, F. C. M. (Eds.) Parâmetros técnicos para produção de sementes florestais. Seropédica: Rioesba - Rede Mata Atlântica de Sementes Florestais, 2007, p. 51-102.

REITZ, R.; KLEIN, R. M.; REIS, A. Projeto Madeira do Rio Grande do Sul. Porto Alegre: SUDESUL, 1988. $525 \mathrm{p}$.

SEMA/UFSM-RS. Governo do Estado. Secretaria Estadual do Meio Ambiente. Relatório Final do Inventário Florestal Contínuo do Rio Grande do Sul. Porto Alegre, 2001. 706p. v.1, 2.

RODERJAN, C. V. Morfologia do estágio juvenil de 24 espécies arbóreas de uma Floresta com Araucária. Curitiba, 1983. 148 f. Dissertação. (Mestrado em Ciências Florestais)-Universidade 
Federal do Paraná, Curitiba, 1983.

SANTANA, D. G.; RANAL, M. A. Análise da germinação: um enfoque estatistico. Brasilia: Ed. Universidade de Brasilia, 2004. 248 p.

SCHNEIDER, P. S. P.; SCHNEIDER, P. R.; FINGER, C. A. G. Crescimento do ipê-roxo, Tabebuia impetiginosa (Mart ex D.C.) Standl. na depressão central do Rio Grande do Sul. Ciência Florestal, Santa Maria, v.10, n. 2, p. 91-100, 2000. SOUZA, L. A. de. Morfologia e anatomia vegetal: célula, tecidos, órgãos e plântula. Ponta Grossa: UEPG, 2003. 259 p.

SOUZA, L. A. de; MOSCHETA, I. S. de. Morfoanatomia do fruto e da plântula de Aspidosperma polyneuron M. Arg. (Apocynaceae). Revista Brasileira de Biologia, São Carlos, v. 52, n. 3, p. 439-447, 1992.

VIDAL, W. N.; VIDAL M. R. R. 4. ed. Botânica - Organografia. Quadros Sinóticos Ilustrados de Fanerógamos. Viçosa: UFV, 2000. 124p.

WIKANDER, T. Mecanismos de dispersion de diasporas de una selva deciduas en Venezuela. Biotropica, St. Louis, n. 16, p. 276-283, 1984.

WRIGHT, S. J.; VAN SCHAIK, C. P. Light and the phenology of tropical trees. American Naturalist, n. 143, p. 192-199, 1994.

ZAR, J. H. Biostatistical Analysis. $5^{\text {th }}$ ed. Hardcover, 2009. 960 p. 